\title{
UM ESTUDO SOBRE A ADAPTAÇÃO DE TEXTOS BÍBLICOS PARA CRIANÇAS EM O MUNDO COLORIDO DA BÍBLIA
}

\section{A STUDY ON THE ADAPTATION OF BIBLICAL TEXTS FOR CHILDREN IN $O$ MUNDO COLORIDO DA BÍBLIA}

Tays de Oliveira ${ }^{1}$

Richarles Souza de Carvalho ${ }^{2}$

RESUMO: Este trabalho busca analisar semelhanças e diferenças entre textos originais da Bíblia e histórias bíblicas adaptadas para crianças, levando em consideração elementos verbais e não verbais. O corpus para a análise é o livro O Mundo Colorido da Bíblia. Como base para a fundamentação teórica, busca-se associar literatura infantil, textos bíblicos vistos como literatura, o processo de adaptação e a relação entre o verbal e o não verbal. A partir disso, o livro é analisado considerando as perdas e ganhos do processo de adaptação em relação ao texto original. No decorrer da pesquisa, pode-se notar que o adaptador exerce grande influência, ainda mais em se tratando de adaptações para o público infantil. Esse adaptador tem sua própria visão de mundo, o que acaba interferindo no objetivo da adaptação para crianças o qual seria partir do olhar da criança. Ainda pode-se observar que a relação entre o verbal e o não verbal não desempenha a conexão de complementaridade que deveria ter, restringindo a imagem à mera ilustração e limitando o texto a uma visão única do adaptador. Sendo assim, fica evidenciado que, no processo de adaptação, alguns elementos importantes são perdidos, até mesmo aspectos literários.

PALAVRAS CHAVE: Adaptação. Literatura Infantil. Bíblia.

ABSTRACT: This work searches to analyze similarities and differences between original texts from a traditional Bible and adapted Biblical stories for children, taking into consideration verbal and nonverbal elements. O Mundo Colorido da Bíblia is the corpus analysis. Theoretical background associates children's literature, biblical texts seen like literature, adaptation processes and verbal and nonverbal relations. From this basis, the book is analyzed, considering losses and gains within the adaptation process towards original text. During the research it is possible to realize that the person who adapts has a great influence over the process, even more it is an adaptation for children. That person who adapts has his own vision of the world and that interferes on the adaptation because children vision of the world is different. Yet, we observed that verbal and nonverbal relation does not represents

\footnotetext{
${ }^{1}$ Graduada em Pedagogia da UNESC. <tays_sx@hotmail.com>

${ }^{2}$ Orientador. Doutor em Ciências da Linguagem. Docente dos cursos de Pedagogia e Letras da UNESC. <rsc@unesc.net>

Saberes Pedagógicos, Criciúma, v. 4, n¹, janeiro/abril 2020.-Curso de Pedagogia- UNESC
} 
correct complementarity connections. Images are mere illustrations, so the whole text is a unique vision from the person who adapts. Therefore, it is evident through the adaption process that some important aspects are lost, even literary aspects.

KEYWORDS: Adaptation. Children's Literature. Bible.

\section{INTRODUÇÃO}

O tema proposto neste artigo foi escolhido a partir da disciplina de Literatura Infanto juvenil, do curso de Pedagogia, quando se observou a relevância das adaptações e que estas geram questionamentos fundamentais em relação a ser ou não algo positivo para a literatura. Dada a relação entre as várias adaptações existentes de clássicos literários, surgiu a curiosidade de investigar as adaptações, mais precisamente em relação às histórias bíblicas literárias que se encontram no meio familiar brasileiro, assim levando ao problema de pesquisa: "Como as histórias bíblicas são adaptadas para o público infantil, levando em consideração elementos verbais e não verbais?”

Vivemos cada vez mais uma realidade em que nada se cria, mas tudo se "adapta". Dessa forma, podemos dizer que as adaptações estão presentes por todos os lados, tanto em ambientes de lazer como no meio educativo. Geralmente, não paramos para pensar nos impactos que isso pode trazer para nossa literatura e se esse recurso vem de fato a "somar". Muitas vezes, o processo de adaptação resulta na perda da essência da obra original, por isso é imprescindível que, ao tratar desse assunto, possamos refletir sobre qual é o objetivo da adaptação.

Nesse contexto de um "mundo" de adaptações, vale citar as histórias bíblicas, talvez estejam entre as mais antigas já adaptadas, e não uma ou duas vezes, mas muitas e para todos os gostos. Mas é claro que em relação às histórias literárias, ela se torna imbatível, pois até mesmo quem não tem crença alguma conhece muitas dessas histórias, seja por meio de mídia, literatura etc. Apesar do aumento relevante de pesquisas da Bíblia como literatura, esse tema ainda não é totalmente comum no meio pedagógico, o que é curioso já que ela é na verdade um grande clássico literário que está arraigado a nossas culturas e mal percebemos. Neste cenário, podemos pensar que mesmo com versões mais atuais como a Bíblia na 
Linguagem de Hoje, ainda existem versões mais rebuscadas que dificultam sua compreensão tanto para adultos como para crianças, o que é comum em relação aos clássicos mais antigos por conta da linguagem.

Neste momento, a adaptação entra em cena, trazendo histórias de forma mais acessível com linguagens e imagens atrativas a quem tiver interesse. Por isso, esta pesquisa tem como objetivo geral: analisar semelhanças e diferenças entre textos originais da Bíblia e histórias bíblicas adaptadas para crianças, levando em consideração elementos verbais e não verbais. E se desenvolve em seus objetivos específicos: conceituar adaptação literária, relacionar histórias bíblicas infantis ao seu texto original, analisar como são retextualizadas histórias bíblicas e os projetos gráficos, e ainda compreender como as imagens dialogam com o texto verbal adaptado.

\section{LITERATURA INFANTIL}

As adaptações já ocupam lugar significativo em nossas vidas há décadas, seja por meio do teatro, música, filmes, literatura etc. Porém, vamos nos ater aqui às adaptações literárias infantis que vêm evoluindo com o passar do tempo e tomando conta de nossas escolas, bibliotecas, livrarias e onde mais se possam encontrar livros e textos.

Nem sempre existiu uma literatura voltada ao público infantil, pois até que a infância fosse concebida ainda não existia a preocupação em "atender" a esse público, como indica Ariès:

\footnotetext{
A descoberta da infância começou sem dúvida no século XIII, e sua evolução pode ser acompanhada na história da arte e na iconografia dos séculos XV e XVI. Mas os sinais de seu desenvolvimento tornaram-se particularmente numerosos e significativos a partir do século XVI e durante o século XVII. (ARIÈS, 1973, p. 65).
}

Com o decorrer deste processo, novos interesses foram surgindo e a preocupação direcionada ao público infantil começou a crescer, uma vez que este demonstrava interesses próprios e uma formação específica. Com esta visão ampliada, não só novas histórias começaram a ser criadas a partir da perspectiva infantil, mas também processos de adaptação de histórias que já existiam foram utilizados e agora ganhavam uma nova roupagem. Esse

Saberes Pedagógicos, Criciúma, v. 4, n¹, janeiro/abril 2020.- Curso de Pedagogia- UNESC 
processo foi evoluindo com o decorrer do tempo e hoje podemos ver diversas adaptações com cores, texturas, ilustrações e o que mais for preciso para atrair a atenção de um público infantil que supostamente se torna cada vez mais exigente por conta das demandas da pósmodernidade, o que pode ser evidenciado no texto corpus de análise: $O$ Mundo Colorido da Bíblia.

Mas afinal o que é literatura infantil? Segundo Parreiras (2009), a literatura é uma arte, como é a pintura, a escultura, a dança, o teatro e a música. Porém, essa arte é diferente das outras, pois exige que o leitor seja alfabetizado. Desse modo, surge uma questão imprescindível de âmbito literário, que é justamente o acesso a essa arte, pois para qualquer outro tipo de arte não é necessário que exista um mediador entre a obra e aquele que irá apreciá-la, porém, neste caso, sem o mediador é impossível que exista o gênero de literatura infantil, como ressalta Cademartori:

Quando se fala em literatura infantil, através do adjetivo, particulariza-se a questão dessa literatura em função do destinatário estipulado: a criança. Desse modo, circunscreve-se o âmbito desse tipo de texto: é escrito para a criança e lido pela criança. Porém, é escrito, empresariado, divulgado e comprado pelo adulto. (CADEMARTORI, 1994, p. 21).

É importante observar que, ao falar de literatura infantil, a relação entre adulto e criança é parte fundamental, uma vez que um depende do outro para que tal gênero exista. Sendo assim, podemos notar que a existência de tal gênero se dá entre a relação de ambos, enquanto a criança depende do adulto para produzir e ter acesso a um livro, o adulto se atém à criança para que possa se aproximar de seu universo, já que é diretamente a ele que a literatura infantil deve se destinar. Nesse sentido, Parreiras (2009, p. 17) ressalta: "Um livro dirigido à criança é um produto do mercado, criado, escrito, ilustrado, produzido e editado por um adulto. Quem leva o livro à criança é também um adulto”.

Estabelecida essa relação, Cademartori e Parreiras deixam evidente que, apesar de a criança ser o foco da literatura infantil, quem tem a responsabilidade de propiciar o acesso a esta literatura é o adulto e cabe a ele fazer a aproximação de várias perspectivas a um universo tão único e complexo como o da criança. 


\section{SABERES PEDAGÓGICOS}

Revista do Curso de Graduaçāo de Pedagogia - Unesc

ISSN 2526-4559

E de que criança se está falando? Como citado anteriormente, a infância é um conceito relativamente novo que, com o decorrer do tempo, vem passando por uma espécie de metamorfose, pois cada época da história é marcada por um novo conceito ou uma nova transformação de conceitos já existentes, como afirma Ariès (1973, p. 48): "Essas variações de um século para outro dependem das relações demográficas. São testemunhos da interpretação ingênua que a opinião faz em cada época da estrutura demográfica, mesmo quando nem sempre pode conhecê-la." Desse modo, é preciso compreender que a infância a qual este trabalho se refere é aquela construída sociologicamente na contemporaneidade.

Da mesma forma que o conceito de infância muda, a literatura infantil acompanha esse processo, uma vez que as características atendem à "demanda" da evolução. É comum em livros mais antigos de literatura infantil encontrar coisas que são consideradas inapropriadas nos dias de hoje, ainda mais em tempos em que o politicamente correto ganhou tanta ênfase, porém na época em que foi escrito poderia ser algo totalmente comum, sem haver motivos para escândalos. O que é escrito hoje pode ser considerado apropriado na atualidade, mas se pudéssemos fazer uma viagem no tempo, tanto para o passado como para o futuro, talvez viesse a causar escândalo ou quem sabe nem seria considerado como literatura infantil. Exemplo disso seriam os contos de Hans Christian Andersen que, apesar de serem classificados como literatura infantil dependendo do texto, podem ser de difícil compreensão; ou os livros de Mark Twain, como As aventuras de Tom Sawyer, também classificados como literatura infantojuvenil, que hoje dificilmente são lidos talvez por uma questão de quantidade de páginas, mas que por outro lado se comparados com livros de J.K Rowling ou George Martin não seriam vistos os mesmos "problemas".

\section{A BÍBLIA COMO TEXTO LITERÁRIO}

Falando em literatura, chegamos às histórias bíblicas. É curioso notar que por muito tempo a Bíblia vem sendo ignorada como literatura por ser um livro religioso, muitas vezes inclusive por alguns religiosos que consideram a classificação pejorativa por ser um 


\section{SABERES PEDAGÓGICOS}

Revista do Curso de Graduaçăo de Pedagogia - Unesc

ISSN 2526-4559

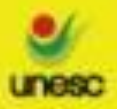

trations

livro sagrado para as religiões. Entretanto, o que não é levado em consideração é que esse livro tem grande teor histórico e cultural do qual se constitui nossa sociedade.

Independentemente de qualquer crença religiosa, o simples fato de vivermos numa nação que faz parte do Ocidente judaico-cristão já nos torna herdeiros da linhagem bíblica. Estamos impregnados de suas histórias e seus ensinamentos. O mínimo que podemos fazer é procurar, pelo menos, transmitir às crianças e aos jovens essa tradição narrativa ancestral. (MACHADO, 2002, p. 34).

A partir desse prisma, a Bíblia pode ser vista diferentemente do que muitos pensam. Não se trata apenas de um livro religioso, ela tem caráter histórico, poético, filosófico etc. Atende aos mais diversos gostos, principalmente em se tratando de literatura infantil e tem uma infinidade de histórias com gigantes e aventuras que é de prender a atenção de qualquer criança. (MACHADO, 2002).

Nesse contexto, é preciso destacar que normalmente as histórias bíblicas chegam até o público infantil através de adaptações, uma vez que dependendo da versão a linguagem original pode ser um tanto quanto rebuscada, com vocabulário arcaico e metáforas difíceis de compreender. Além disso, as ilustrações das chamadas Bíblias infantis se diversificam, pois ganham as mais variadas cores e texturas que as tornam mais atraentes e interessantes para o público infantil. Machado (2002) ainda destaca que, através da Bíblia, as crianças podem ter uma nova dimensão da leitura, já que elementos bíblicos são referenciados com frequência nas mais diferentes obras artísticas e até em muitas expressões da língua portuguesa como, por exemplo, os termos "lavar as mãos", "tempo de vacas magras", "mudar da água para o vinho" ou como o soneto de Camões sobre o amor de Jacó por Raquel.

É preciso salientar, ainda, que a própria Bíblia a qual temos acesso se trata de uma tradução, pois segundo Larry Walker (1998), a Bíblia foi originalmente escrita em hebraico, aramaico e grego, diversificando-se em autores de épocas diferentes. Desde então, várias traduções foram feitas até chegar a nossa língua. Aqui já ficam evidentes alguns pontos os quais são tratados na próxima seção em relação à adaptação. Walker (1998, p. 294) afirma que "A vivacidade, concisão e simplicidade da língua hebraica torna-a difícil de ser traduzida em sua inteireza". Isso evidencia possíveis problemas na tradução, o que pode se tornar ainda mais complexo na adaptação.

Saberes Pedagógicos, Criciúma, v. 4, nº1, janeiro/abril 2020.- Curso de Pedagogia- UNESC 
Por mais que o tradutor se esforce para alcançar a diversidade de sentidos do texto original, nenhuma língua pode se igualar com objetos, acontecimentos e conceitos da mesma forma que outra, pois elas dependem de fatores culturais (ELLIOT, 1998). Por esses fatores históricos que dificultam um termo apropriado para se referir à Bíblia, decidimos utilizar o termo "original" quando se trata de textos bíblicos.

A partir de tais considerações, é difícil não notar a ação que a adaptação exerce na literatura, já que textos adaptados podem abrir novos caminhos de leitura. Aí se evidencia a influência do adaptador (adulto), pois cada adaptação pode mostrar diferentes histórias, feitas por pessoas e visões distintas que acabam agregando diversos sentidos à história original, em alguns casos até se distanciando, ainda que a adaptação não envolva necessariamente textos de línguas diferentes.

\section{ADAPTAÇÕES LITERÁRIAS}

É neste cenário de intermediação do adulto que as adaptações entram em ação, já que é obviamente do olhar dele que essa mudança ocorre. Acontece que muitos autores, segundo Hutcheon (2011), divergem em relação ao conceito de adaptação e qual sua real função. Alguns consideram como uma melhoria de sua obra original, outros veem como algo depreciativo ou secundário, já em alguns casos é considerada como algo que vem para somar. Não cabe aqui favorecer ou desmerecer uma teoria ou outra, pois o objetivo deste estudo é compreender de que forma a adaptação é relevante às histórias bíblicas infantis, então podemos partir de uma definição padrão trazida pelo dicionário Houaiss (2009, p. 47), que define adaptação como "ajuste de uma coisa a outra", ou seja, adaptação e obra original são coisas diferentes e, por isso, talvez seja incabível dizer o que é melhor ou pior.

Quanto a esse novo olhar, Hutcheon evidencia que o próprio adaptador, por sua vez, acaba pendendo à parcialidade, como mostra a seguir:

Tal como a tradução, a adaptação é uma forma de transcodificação de um sistema de comunicação para outro. Com as línguas, nós nos movemos, por exemplo, do inglês para o português, e conforme vários teóricos nos ensinaram. A tradução inevitavelmente altera não apenas o sentido literal, mas também certas nuances,

Saberes Pedagógicos, Criciúma, v. 4, n¹, janeiro/abril 2020.- Curso de Pedagogia- UNESC 
associações e o próprio significado cultural do material traduzido. Com as adaptações, as complicações aumentam ainda mais, pois as mudanças geralmente ocorrem entre mídias, gêneros e, muitas vezes, idiomas e, portanto, culturas. (HUTCHEON, 2011, p. 9).

Somado a esse processo, é preciso considerar que a literatura infantil, para que se faça valer do nome, necessita da visão direcionada à criança, sobre a criança e de preferência como se fosse da própria criança, considerando suas particularidades e sua forma de ver o mundo. Isso torna o processo de adaptação ainda mais complexo, pois o adaptador precisa se aproximar ao máximo do olhar da criança e tentar ver o mundo a partir do seu olhar.

Um problema comum é que, ao passar por essa "passagem" da história para o olhar de uma criança, em alguns casos, o adaptador acaba caindo na armadilha da "suavização" de conteúdo, segundo Hutcheon (2011), como se a criança não fosse capaz de compreender algo ou como se houvesse a necessidade de "protegê-la" das verdades contidas em sua história original. Isso pode ser visto frequentemente em diversas adaptações de histórias infantis tanto na parte verbal como na não verbal, e não por acaso as mesmas questões são evidenciadas nas histórias bíblicas aqui analisadas.

Outro ponto até então não citado é a questão do não verbal, que será pormenorizado na próxima seção, porém é importante relacionar aqui, pois se trata de algo frequentemente presente no processo de adaptação de textos para o universo infantil. As imagens acabam muitas vezes atribuindo novos significados à leitura do verbal e, consequentemente, podem também cair na mesma "armadilha" da "suavização" de significados. Desse modo, o cuidado do adaptador (escritor/ilustrador) deve ser dobrado, já que sua preocupação não se baseia apenas no verbal, mas também no não verbal.

Partindo daí, presume-se que a adaptação depende e muito da particularidade de quem a faz e, portanto, sempre carrega consigo uma visão pessoal à obra, mesmo que inconscientemente. Dessa forma, surge uma espécie de paradoxo que revela uma obra originada de outra (adaptação) e que ao mesmo tempo é como uma nova criação. De tal modo, Hutcheon (2011) destaca que, embora o termo "adaptação" possa parecer simples, ele é mais complexo do que aparenta, já que é usado tanto para o produto como para o processo e acaba sendo muitas vezes confundido com termos como a tradução. 
Logo, a adaptação para literatura infantil se torna uma tarefa muito mais difícil, pois ela exige recriação partindo do olhar da criança, mas deve fluir de um adulto que embora já tenha sido criança ou possa conviver no meio delas, já tem seu próprio modo de ver o mundo. Assim sua tarefa está em se aproximar ou reaproximar dessa infância trazendo uma "fusão" de olhares. É justamente sobre isso que Parreiras (2009) explana em seu livro Confusão de Línguas na Literatura, onde ela ressalta que o olhar da criança não é o mesmo que o do adulto, o que provoca uma incompreensão entre as duas linguagens.

\section{RELAÇÃO ENTRE O VERBAL E O NÃO VERBAL}

Seguindo a complexidade da adaptação, deparamo-nos com a relação entre o verbal e o não verbal, já que no caso da literatura infantil é quase regra que ambos se encontrem na maioria das obras. Primeiramente, é preciso salientar que o não verbal aqui tratado se refere à ilustração, pois podemos considerá-la como característica fundamental em Bíblias infantis. Outro ponto a ser considerado é que a Bíblia, em seu original, tem como característica justamente o contrário, pois é constituída apenas pelo verbal, ou seja, pela palavra escrita. Essa ligação entre o verbal e o não verbal se mostra cada vez mais importante, já que ambos constituem uma conexão que proporciona uma compreensão maior do que é dito.

\footnotetext{
Nas relações entre imagens e palavras predomina a complementaridade. Quer dizer, as mensagens são organizadas de modo que o visual seja capaz de transmitir tanta informação quanto lhe é possível, cabendo ao verbal confirmar as informações que já passaram visualmente e acrescentar informações específicas que o visual não é capaz de transmitir. (SANTAELLA, 2002, p. 53)
}

$\mathrm{Na}$ adaptação, essa complementaridade pode atribuir novos sentidos ao texto que antes não poderiam ser vistos, como no caso da Bíblia. Por sua vez, em livros infantis, muitas vezes a presença da imagem se torna muito mais significativa do que o texto verbal, exemplo disso é o famoso livro de Ziraldo Flicts, que apesar de não ser uma adaptação foi constituído em sua maior parte por imagens e fez muito sucesso. Acontece que em alguns casos essa tradução intersemiótica pode acabar agregando sentidos talvez contraditórios, o que leva ao questionamento de quais impactos essa tradução pode gerar. Carvalho et al. $(2018$, p. 3)

Saberes Pedagógicos, Criciúma, v. 4, n¹, janeiro/abril 2020.- Curso de Pedagogia- UNESC 
afirmam que, "além de admitirmos a construção de sentidos por meio das imagens, principalmente na contemporaneidade, a relação da palavra (verbal) com outras semioses não verbais é algo que não se pode deixar de lado em investigações discursivas; em alguns casos tal relação é constitutiva." E como citado anteriormente, esses sentidos são, em um primeiro momento, atribuídos pelo próprio adaptador.

Ainda assim a relação entre verbal e não verbal está longe de ser algo negativo, pelo contrário, ela propicia uma nova experiência ao leitor, e quando se diz leitor, é preciso lembrar que o público-alvo do qual estamos tratando nem sempre são crianças alfabetizadas. Isso eleva ainda mais o valor da conexão entre palavras e imagens, pois uma criança parcialmente alfabetizada pode compreender melhor a história pelas ilustrações, e da mesma forma a criança que não é alfabetizada pode compreender ou até dar diversas interpretações à história, ou seja, a leitura pode ser feita de uma forma ou de outra, ou ainda na complementaridade de ambas as semioses. "Um texto não tem que se sobrepor à ilustração. E a ilustração não tem que ficar presa ao texto. Uma ilustração não deve ser mera legenda. Uma ilustração não é um enfeite nem um acessório a mais no livro. " (PARREIRAS, 2009, p. 89). Por conseguinte, pode-se dizer que ambas são partes imprescindíveis na literatura infantil, pois não se trata do que é melhor ou pior, ou do que aparece mais no livro, e sim de signos diferentes que juntos constroem sentidos no processo de leitura.

\section{UMA ANÁLISE DE O MUNDO COLORIDO DA BÍBLIA}

Esta pesquisa tem como objetivo analisar semelhanças e diferenças entre textos originais de uma Bíblia tradicional e histórias bíblicas adaptadas, levando em consideração elementos verbais e não verbais em $O$ Mundo Colorido da Bíblia, de Charlotte F. Lessa ${ }^{3}$. Também serão observados e problematizados perdas e ganhos nesse processo de adaptação. Para comparação de análise, foram utilizadas três versões da Bíblia: Bíblia Almeida Revista e

\footnotetext{
${ }^{3}$ Charlotte Fermum Lessa nasceu em Bremen, Alemanha. Aos três anos mudou-se para o Brasil, fixando residência em São Paulo. É casada com Rubens Lessa e tem três filhas. É psicopedagoga, escritora, tradutora e fundadora do Instituto de Desenvolvimento Humano Kathia Lessa, nome dado em homenagem a uma de suas filhas.
}

Saberes Pedagógicos, Criciúma, v. 4, nº1, janeiro/abril 2020.-Curso de Pedagogia- UNESC 
Atualizada, Nova Tradução na Linguagem de Hoje e Nova Versão Internacional. A escolha se manteve por usar as mesmas versões utilizadas por Charlotte F. Lessa em sua adaptação.

Para a análise, foram utilizadas as seguintes questões como roteiro norteador: Quais os títulos das histórias? Quais partes da Bíblia foram escolhidas para a adaptação e por quê? Como os textos verbais se relacionam com os não verbais? As imagens são meras ilustrações ou um complemento textual não verbal? O vocabulário é simples ou complexo? Até que ponto a adaptação se mantém livre em relação ao texto original ${ }^{4}$ ?

Como o próprio nome já indica, O Mundo Colorido da Bíblia é realmente colorido se visto a partir das várias ilustrações trazidas por Jo Card $^{5}$, ilustrador do livro, afirmando o que Machado (2002, p. 38) diz: "Hoje em dia, com maravilhosas ilustrações coloridas, o efeito sobre a garotada deve ser ainda mais forte, transportando o pequeno leitor para um ambiente completamente diferente do que ele está acostumado a ver ao seu redor". Essas ilustrações são encontradas praticamente em todo o livro, preenchendo até mesmo páginas que em outras publicações normalmente são reservadas em branco.

A ideia que o livro apresenta inicialmente é trazida por personagens da revista Nosso Amiguinho ${ }^{6}$, que se trata justamente de uma turma de crianças que são muito amigas. No contexto do livro, essas crianças falam ao leitor que irão apresentar $O$ Mundo Colorido da Bíblia.

No decorrer de cada história não fica claro quem está contando, se são as próprias crianças, mas pelo fato de uma vez ou outra alguns desses personagens aparecerem nos cenários, fica a ideia de que eles estão não apenas contando, mas também se imaginando no meio da história. Outro ponto que dá a entender que a narrativa é feita pelos personagens do Nosso Amiguinho é que as falas dos personagens bíblicos adultos são infantilizadas. Por

\footnotetext{
${ }^{4}$ Como mencionado anteriormente, é importante relembrar que o termo "original", utilizado frequentemente neste trabalho, serve apenas para facilitar a escrita, pois sabe-se que a Bíblia da qual temos acesso trata-se de uma tradução.

${ }^{5}$ João Luiz Cardozo (Jo Card) nasceu em Criciúma - Santa Catarina, e deixou cedo sua casa para trabalhar como ilustrador. De 1979 a 1989 trabalhou para a CPB (Casa Publicadora Brasileira), ilustrando livros e revistas. Mudou-se para Portugal e trabalhou como free-lancer para a Publicadora Atlântico, lá também produziu animações em três dimensões para a televisão portuguesa. Foi o artista responsável pela revista infantil Nosso Amiguinho com a qual colabora até hoje. Retornou para o Brasil para concluir O Mundo Colorido da Bíblia.

${ }^{6}$ Nosso Amiguinho é uma revista educativa brasileira, publicada mensalmente há 60 anos pela Casa Publicadora Brasileira, editora pertencente à Igreja Adventista do Sétimo Dia. A Casa Publicadora Brasileira é a mesma editora do livro que está sendo analisado neste artigo.
}

Saberes Pedagógicos, Criciúma, v. 4, nº1, janeiro/abril 2020.-Curso de Pedagogia- UNESC 
exemplo, na história intitulada Deus em ação, que conta sobre a criação do mundo, Deus diz "a Terra precisa ficar bem bonita", o que gera a impressão de ser dita por uma criança e não por um adulto. É interessante pensar no questionamento que Parreiras (2009, p. 17) faz: "Será que o que os adultos criam agradam à criança?" Talvez sim, talvez não, mas e se o livro for contado por uma criança? Será que isso o torna mais agradável para ela?

A primeira história bíblica presente no livro foi intitulada $O$ anjo que queria ser Deus. Essa história conta de forma breve como Lúcifer, estando entre os anjos mais lindos e poderosos, se corrompeu por sua inveja e foi expulso dos céus. O curioso é que essa não é a primeira história registrada na Bíblia, porém é a primeira escolhida para o início da bíblia infantil.

Como o livro é apresentado como a história da humanidade, talvez essa inversão na ordem seja uma tentativa de expor a história de forma cronológica e automaticamente mais fácil de compreensão, já que na Bíblia algumas histórias não se encontram de forma cronológica. Isso seria o que Hutcheon (2011) chama de "suavização" vista a partir dos olhares conservadores. Apesar disso, a forma de divisão entre Antigo e Novo Testamento utilizada na Bíblia se manteve também no livro.

Quanto às escolhas das histórias, não fica evidente por quais motivos foram incluídas ou não, mas dentro do tema da história da humanidade, pode-se entender que foi narrado o necessário para manter uma linha histórica contínua.

Quanto à adaptação da escrita, percebe-se um padrão mantido, onde foram utilizados entre dois e três capítulos da Bíblia para cada história do livro. Porém, os textos são resumidos ao extremo, deixando em alguns casos detalhes importantes de fora. Se essa condensação fosse ilustrada por números, poderíamos dizer que a cada quarenta versos da Bíblia, quatro são escolhidos como essência da história e o resto é descartado. Contudo, apesar de a história ser bem resumida, a escrita não é assim tão sintética, pois o texto é "embelezado" a partir das escolhas de trechos possivelmente para torná-lo mais atrativo à criança.

Hutcheon (2011) diz que as adaptações podem ser vistas pejorativamente por conter mudanças da história original. Isto aconteceria devido a fatores um tanto românticos que consideram uma traição fazer uma alteração na obra original, porque é comum ainda se

Saberes Pedagógicos, Criciúma, v. 4, nº 1, janeiro/abril 2020.- Curso de Pedagogia- UNESC 
confundir os termos tradução e adaptação. Como exemplo de eventuais mudanças no "enfeitar" do texto, foram encontradas algumas contradições em relação ao original, que se vê no caso da história Deus em Ação. No sexto dia Deus ordena que surjam os mais diversos animais e cita vários nomes deles, porém, segundo Gênesis (2:19), Deus apenas diz para que os animais surjam e manda que Adão nomeie cada um deles, pois até então eram chamados apenas de "seres viventes" (BÍBLIA, 1993).

No que diz respeito aos detalhes deixados de fora, o resumo excessivo deixa em alguns momentos a impressão de que a história está incompleta; e de fato está, se comparada ao original. Exemplificado: o capítulo Resultados da Desobediência, que conta a história do pecado desde Adão e Eva até a arca de Noé, já inicia com a expulsão de Adão e Eva do Jardim do Éden por terem comido o fruto da árvore proibida, sem dar uma explicação prévia de onde essa árvore surgiu e o porquê.

Isso traz a impressão, descrita por Machado (2002), de um Deus moralista que queria um povo obediente a Ele. Ainda na mesma história sobre desobediência, Caim e Abel (filhos de Adão e Eva) são citados: um como fiel a Deus e outro como o que não gostava de obedecer, mas o fato de Caim ter matado Abel nem foi mencionado. Não se sabe por que esses trechos não foram incluídos, talvez a ideia de que o primeiro homicídio mencionado na Bíblia foi entre irmãos seja alarmante (pois outros tipos de homicídio não foram deixados de fora do livro), ou possa ser considerado mais um caso de "suavização". O fato é que seja por achar impróprio, por suavizar, ou simplesmente ter sido deixado de lado porque o texto precisava ser mais objetivo, alguns sentidos podem ter se perdido no processo da adaptação, e tais sentidos nem sempre são descartáveis.

Em relação às imagens, no geral são ilustrações bem trabalhadas e coloridas, possuem um belo traço, fazendo com que a escrita frequentemente se "misture" aos desenhos. No decorrer de cada história, pode ser notado que as imagens se mantêm apenas como ilustração, ou seja, descrevem apenas o que a escrita já diz. Parreiras (2009, p.89) afirma que "um texto não tem que se sobrepor à ilustração. E a ilustração não tem que ficar presa ao texto. Uma ilustração não deve ser mera legenda. Uma ilustração não é um enfeite nem um acessório a mais no livro".

Saberes Pedagógicos, Criciúma, v. 4, nº1, janeiro/abril 2020.- Curso de Pedagogia- UNESC 
Um exemplo da relação entre ilustração e texto verbal é a história $E$ o Galo Cantou, que conta sobre o personagem Pedro, que negou três vezes a Jesus, e em apenas uma página são descritas três ações: (1) o canto do galo, (2) Jesus e Pedro se olham, (3) Pedro ficou com profunda tristeza. Os três acontecimentos são ilustrados na página, nada mais nada menos. Interessante observar aqui que as imagens poderiam ser mais bem utilizadas, ainda mais em se tratando de um texto escrito tão resumido onde as imagens poderiam "falar" o que não coube em palavras.

A impressão que fica é que os trabalhos de escrita e de ilustração foram feitos separadamente, e talvez de fato o tenham sido. O caso é que falta o "diálogo" entre imagem e escrita, que deveria funcionar como um casamento que age em conjunto e complementaridade e não separadamente, como citado por Santaella (2002).

Outro ponto observado é em relação ao aspecto físico nas ilustrações dos personagens, que possuem características bem estereotipadas, como Jesus de pele clara e olhos azuis, Eva loira também de olhos azuis. Vários outros personagens são apresentados com características bem diferentes do que seriam historicamente falando. Além disso, em alguns casos, essa representação fica realmente exagerada, deixando os personagens com mais aparência de europeus do que hebreus como evidenciado na imagem da página 95 que mostra Joquebede e seu bebê Moisés, ambos hebreus, os quais foram ilustrados com pele e olhos claros etc. 


\section{SABERES PEDAGÓGICOS}

Revista do Curso de Graduaçāo de Pedagogia - Unesc

ISSN 2526-4559

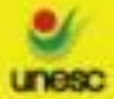

Thtrations

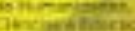

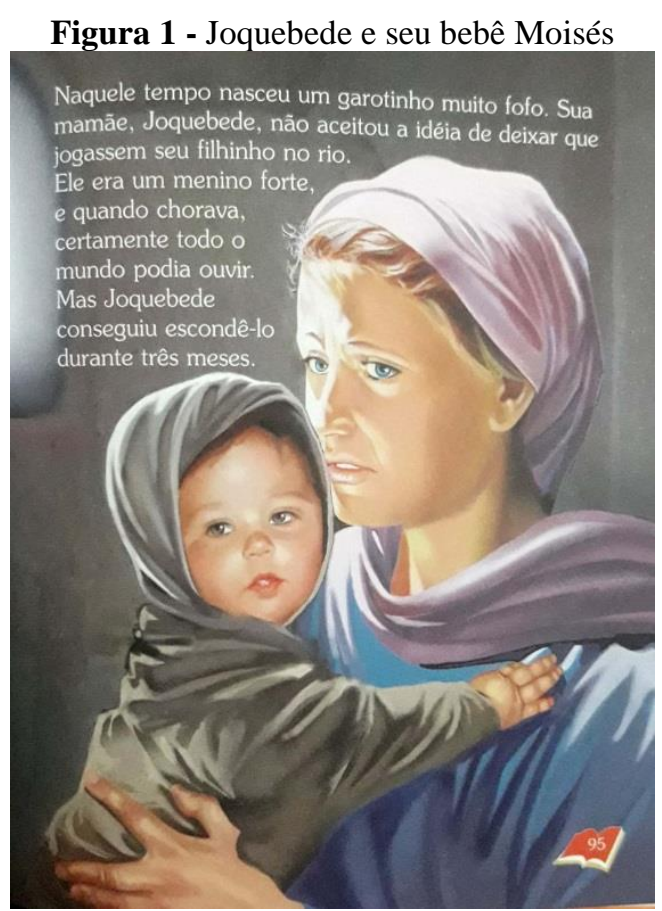

Fonte: Jo Card, 2004.

É preciso considerar de que forma essas imagens estereotipadas podem refletir na mente da criança que lê e está cada vez mais submersa em um mercado cheio de imagens préconcebidas. Tal mercado inclusive dita o que é bonito, verdadeiro ou o que é "normal". Essas características fazem pensar no que Santaella (2005) diz em relação a um jogo de cores e design que traduz uma semiótica que faz o indivíduo escolher um produto e não um conteúdo, já que ele apresenta um projeto gráfico muito bonito, um layout agradável, textos fáceis de compreensão com direito a capa dura e lindas ilustrações. Talvez o livro que analisamos se adeque mais a um produto de mercado que atende às demandas que lhe convém, do que algo que esteja preocupado em ser literário ou religioso.

No processo de adaptação, ficou evidente a influência direta do adaptador sobre a obra, tal qual Parreiras (2009) caracterizou como uma verdadeira "confusão de línguas". Se a adaptação depende da visão de mundo do adaptador e consequentemente o adaptador é influenciado por fatores culturais, como então manter a imparcialidade nesse processo? Elliot (1998) afirma que não há como traduzir sem interpretar, e que se esse fosse o caso a "vida" do tradutor seria muito mais simples. Da mesma maneira, a "vida" do adaptador seria muito mais simples se conseguisse adaptar uma obra sem perder sua essência, acontece que sua própria

Saberes Pedagógicos, Criciúma, v. 4, n¹, janeiro/abril 2020.- Curso de Pedagogia- UNESC 


\section{SABERES PEDAGÓGICOS}

Revista do Curso de Graduaçāo de Pedagogia - Unesc

ISSN 2526-4559

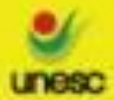

Gotes nuevers

visão de mundo altera sua interpretação, dando novos sentidos ao que foi escrito. Contudo, aparentemente o problema não são os novos sentidos em si, mas a perda de sua essência, pois como Parreiras (2009) indica a literatura é arte. Se for essa a real essência certamente o livro em análise se perdeu no processo da adaptação, já que a dimensão doutrinária, pedagógica se sobressaiu em relação à dimensão literária. Talvez a pretensão deste livro seja apenas de tornar a Bíblia mais acessível ao público infantil independente de quais reflexos possa causar à literatura.

\section{CONCLUSÃO}

O presente estudo possibilita a reflexão para o estudo da literatura, já que cada vez mais as adaptações se encontram presentes em nosso dia-a-dia. A influência trazida pelo adaptador vai se mostrando no decorrer da análise; suas crenças, sua criação, seu modo de ver o mundo gradativamente expõem ainda que involuntariamente, seus pensamentos ou interesses.

Neste cenário, surge a necessidade de rever até que ponto o adaptador pode deixar sua própria visão de mundo para aderir à visão de mundo da criança, já que falamos de seres humanos naturalmente distintos, pois ainda que um dia tenhamos sido crianças, nos constituímos adultos com o decorrer do tempo e isso é irreversível.

Partindo do objetivo de analisar semelhanças e diferenças entre textos originais da Bíblia e histórias bíblicas adaptadas, levando em consideração elementos verbais e não verbais, notamos que, apesar da relação que deve haver entre texto verbal e não verbal, no exemplar analisado O Mundo Colorido da Bíblia não houve "diálogo" entre as duas partes. Isso pode nos levar a pensar que no processo a relação entre adaptador e ilustrador deveria ser a mesma relação entre texto verbal e não verbal, ou seja, uma relação construtiva, onde um complementa o outro. Além disso, podem ocorrer eventuais "traições" em relação ao texto original, por isso é imprescindível manter em mente que a adaptação não é a mesma coisa que a obra original, portanto não há como compará-las diretamente.

Ainda que saibamos da relação que deve haver entre ambas as partes, fica evidente que adaptar exige reflexão em um contexto geral, já que esse processo envolve não

Saberes Pedagógicos, Criciúma, v. 4, nº 1, janeiro/abril 2020.- Curso de Pedagogia- UNESC 
apenas visões de mundo diferentes, mas também de culturas e tempos que se modificam constantemente. Talvez seja justamente por isso que a adaptação é um processo.

É importante ponderar que o processo de adaptação pode sim sofrer perdas a partir do momento em que se perde a essência de arte, mas isso não significa que uma adaptação não é literatura; no caso deste estudo, esse fato não ocorreu.

Por isso, se repensada e estudada mais profundamente, a adaptação pode encontrar caminhos que unam a acessibilidade supostamente estimada em $O$ Mundo Colorido da Bíblia, sem que se perca a essência dos textos originais. Afinal, se a adaptação fosse um processo simples, certamente não haveria tantas controvérsias dentro de um mesmo tema.

\section{REFERÊNCIAS}

ARIÈS, Philippe. História social da criança e da família. Trad. Dora Flaksman. 2. ed. Rio de Janeiro: LTC, 1981.

BÍBLIA SAGRADA. Trad. João Ferreira de Almeida. Ed. Revista e Atualizada no Brasil. Barueri: Sociedade Bíblica do Brasil, 1993.

CADEMARTORI, Lígia. O que é literatura infantil. 6. ed. São Paulo: Brasiliense, 1994.

CARVALHO et al. Discurso, Imagem e Escrita: Transfigurações Estéticas. Vitória: EDUFES, 2018. (No prelo).

ELLIOT, Raymond. Tradução da Bíblia. In: COMFORT, Philip Wesley (org.). A origem da Bíblia. Trad. Luís Aron de Macedo. Rio de Janeiro: Casa Publicadora das Assembleias de Deus, 1998.

HOUAISS, Antônio; VILLAR, Mauro; FRANCO, Francisco Manoel de Mello. Dicionário Houaiss da Língua Portuguesa. Rio de Janeiro: Objetiva, 2009.

HUTCHEON, Linda. Uma teoria da adaptação. Trad. André Cechinel. 2. ed. Florianópolis: Ed. UFSC, 2011.

LESSA, Charlotte Fermum. O mundo colorido da Bíblia. 12. ed. Tatuí: Casa Publicadora Brasileira, 2004.

Saberes Pedagógicos, Criciúma, v. 4, nº1, janeiro/abril 2020.- Curso de Pedagogia- UNESC 
MACHADO, Ana Maria. Como e por que ler os clássicos universais desde cedo. Rio de Janeiro: Objetiva, 2002.

PARREIRAS, Ninfa. Confusão de línguas na literatura: o que o adulto escreve, a criança lê. Belo Horizonte: RHJ, 2009.

SANTAELLA, Lucia. Semiótica aplicada. São Paulo: Pioneira Thomson Learning, 2002.

WALKER, Larry. As Línguas Originais da Bíblia. In: COMFORT, Philip Wesley (org.). A origem da Bíblia. Trad. Luís Aron de Macedo. Rio de Janeiro: Casa Publicadora das Assembleias de Deus, 1998. 